\title{
Short-term efficacy of different chemotherapy regimens in the treatment of advanced gastric cancer: a network meta-analysis
}

\author{
Mi-Ma Duo-Ji ${ }^{1}$, Ba-Sang Ci-Ren ${ }^{1}$, Zi-Wen Long ${ }^{2,3}$, Xiao-Hua Zhang ${ }^{1}$ and Dong-Lin Luo ${ }^{1}$ \\ ${ }^{1}$ Department of Medicine, Shigatse People's Hospital, Shigatse 857000, P.R. China \\ ${ }^{2}$ Department of Gastric Cancer and Soft-Tissue Sarcoma Sugery, Fudan University Shanghai Cancer Center, Shanghai \\ 200032, P.R. China \\ ${ }^{3}$ Department of Oncology, Shanghai Medical College, Fudan University, Shanghai 200032, P.R. China \\ Correspondence to: Zi-Wen Long, email: longziwensh@126.com \\ Keywords: gastric cancer, fluorouracil, capecitabine, S-1, chemotherapy
}

Received: July 11, 2016

Accepted: November 14, 2016

Published: January 14, 2017

Copyright: Duo-Ji et al. This is an open-access article distributed under the terms of the Creative Commons Attribution License 3.0 (CC BY 3.0), which permits unrestricted use, distribution, and reproduction in any medium, provided the original author and source are credited.

\section{ABSTRACT}

Objective: A network meta-analysis was performed to compare the short-term efficacy of different chemotherapy regimens in the treatment of advanced gastric cancer.

Methods: Randomized controlled trials of different chemotherapy regimens for advanced gastric cancer were included in this study. Network meta-analysis combined direct evidence and indirect evidence to evaluate the odds ratio and draw surface under the cumulative ranking curves of different chemotherapy regimens in advanced gastric cancer.

Results: The results of surface under the cumulative ranking curves showed that S-1 and capecitabine regimens were better than fluorouracil. As for multidrug combination regimens, the disease control rate of cisplatin + capecitabine, docetaxel + cisplatin + fluorouracil and etoposide + cisplatin + capecitabine regimens were relatively better, while fluorouracil + adriamycin + mitomycin regimen was relatively poorer when compared with cisplatin + fluorouracil regimen. Additionally, the overall response ratio of cisplatin + capecitabine, paclitaxel + fluorouracil, docetaxel + cisplatin + fluorouracil and etoposide + cisplatin + fluorouracil regimens were relatively better, while the disease control rate of fluorouracil + adriamycin + mitomycin regimen was relatively poorer when compared with cisplatin + fluorouracil regimen. Furthermore, the results of cluster analysis demonstrated that cisplatin + capecitabine, etoposide + cisplatin + capecitabine, S-1 + paclitaxel and S-1 + irinotecan chemotherapy regimens had better disease control rate and overall response ratio for advanced gastric cancer patients.

Conclusion: This network meta-analysis clearly showed that multi-drug combination chemotherapy regimens based on capecitabine and S-1 might be the best chemotherapy regimen for advanced gastric cancer.

\section{INTRODUCTION}

Gastric cancer $(\mathrm{GC})$ is the $4^{\text {th }}$ most common malignant disease and the $2^{\text {nd }}$ most frequent cause of cancer-related deaths around the world [1]. GC is accepted as a pathophysiologically heterogeneous disease, which is associated with hematogenous metastasis, predominant lymphatic spread, or intra-abdominal spread [2]. There are approximately one million new cases annually worldwide and 850,000 deaths from GC, or about $12 \%$ deaths of all cancer [3]. GC is a multifactorial disease caused by environmental and lifestyle factors, other recognized risk factors include smoking, obesity, dietary factors, radiation, Helicobacter pylori infection, pernicious anemia and partial gastrectomy, etc. [4]. Early detection is possible with screening, but most GC patients are diagnosed at 
an inoperable advanced stage which requiring palliative chemotherapy [5]. The most widely used drugs as single agents for chemotherapy are fluorouracil, doxorubicin, cisplatin, mitomycin $\mathrm{C}$, epirubicin, and etoposide, and newer chemotherapeutic agents include the taxanes, oxaliplatin oral fluoropyrimidines, and irinotecan [6]. Despite the advances achieved over the recent decades, the prognosis of patients with advanced GC (AGC) remains poor [7]. New chemotherapy regimens are desperately needed for the benefit of improving the dismal prognosis of AGC.

Currently, there is no globally accepted chemotherapy regimen for AGC, some are used as single agents, while others are used as part of combination regimens. Fluorouracil is one of the most widely used agents in the treatment of AGC, and it is a part of all the primary multidrug regimens that have been reported [8]. Fluorouracil monotherapy, as a standard treatment for AGC, is associated with manageable toxicity, a response rate of approximately $20 \%$, and OS times of between 5 7 months in phase III randomized studies [9]. Recently, capecitabine and S-1, belonging to oral fluoropyrimidines, are suggested to be more tolerable than fluorouracil; and both of them showed exhibit antitumor activity against AGC [10-12]. Capecitabine (Xeloda, F. Hoffmann-La Roche) is known as an oral fluoropyrimidine, which is designed to mimic a continuous infusion of fluorouracil, and it has shown good response rates in AGC patients when given as monotherapy or in combination with other agents in phase II studies [6]. Study has shown that replacing fluorouracil with capecitabine plus cisplatin avoids the need for continuous infusions and the combinations of two agents have few overlapping toxic effects [13]. S-1 is a novel oral fluoropyrimidine consisting of a tegafur (5-FU prodrug), 5-chloro-2, 4-dihydroxypyridine (the dihydropyrimidine dehydrogenase inhibitor) and potassium oxonate (suppresses the gastrointestinal toxicity of tegafur) [14]. In 2007, one phase III trials in Japan (the JCOG9912 trial) demonstrated that S-1 was not inferior to fluorouracil [15]. The other was the SPIRITS trial, which suggested that the combination therapy of S-1-plus-cisplatin was superior to S-1 monotherapy [12]. Since there are controversies in different studies, no consensus has been reached on the optimal chemotherapy regimen in the treatment of AGG in terms of single drug chemotherapy regimen and multi-drug combination chemotherapy regimens based on fluorouracil, capecitabine and S-1.

Network meta-analysis is a relatively new statistical technique that gives access to compare both direct and indirect evidence, even when two of the interventions have not been directly compared [16]. Network metaanalysis can summarize randomized clinical trials (RTCs) of several different treatment strategies, and supply point estimates for their association with a given endpoint, together with an estimate of incoherence. Therefore, we performed a network meta-analysis to compare the shortterm efficacies of different chemotherapy regimens in the treatment of AGC.

\section{RESULTS}

\section{Baseline characteristics of included study}

Through electronic databases, 3791 relevant studies were initially identified. We excluded 684 studies for duplicates, 101 for non-human studies, 2420 for no relation to research topic. The remaining 586 articles were further excluded according to the following factors: 124 studies related to targeted therapy, 287 studies related to surgical treatment and 110 studies related to radiotherapy. Eventually, 35 RCTs, published between 1991 and 2014, were eligible for this network meta-analysis [11, 17-50]. These 35 RCTs altogether included 4555 GC patients treated with twenty-four chemotherapy regimens including cisplatin + fluorouracil $(\mathrm{CF})$, docetaxel + cisplatin (DC), irinotecan + cisplatin $(\mathrm{CI})$, cisplatin + capecitabine (CX), S-1 + cisplatin (S-1C), docetaxel + fluorouracil (DF), paclitaxel + fluorouracil (PF), fluorouracil + leucovorin (FL), docetaxel + oxaliplatin (DO), S-1 + irinotecan (S-1I), S-1 + paclitaxel (S-1P), etoposide + adriamycin + cisplatin (EAC), docetaxel + cisplatin + fluorouracil (DCF), etoposide + cisplatin + fluorouracil (ECF), fluorouracil + adriamycin + mitomycin (FAM), fluorouracil + adriamycin + methotrexate (FAMTX), etoposide + leucovorin + fluorouracil (ELF), fluorouracil + leucovorin + irinotecan (FLI), etoposide + cisplatin + capecitabine $(\mathrm{ECX})$, fluorouracil + leucovorin + cisplatin (FLC), and cisplatin + etoposide + leucovorin + fluorouracil (CELF), and the majority of patients received $\mathrm{CF}$ and FAMTX chemotherapy regimens (Figure 1a1b). Of these 35 enrolled studies, 15 studies were from Caucasians, and 20 studies were from Asians; additionally, 29 studies were two-arm trials and 6 studies were threearm trials. The baseline characteristics of included studies are displayed in Table 1.

\section{Pairwise meta-analysis for short-term efficacy of twenty-four chemotherapy regimens in the treatment of advanced gastric cancer}

We carried out direct pairwise comparisons for the short-term efficacies of twenty-four chemotherapy regimens in the treatment of $\mathrm{AGC}$, and the results suggested that the efficacies of fluorouracil, FAM and FAMTX chemotherapy regimens were relatively poorer in DCR of AGC patients when compared with CF regimen (fluorouracil: $\mathrm{OR}=0.37,95 \% \mathrm{CI}=0.17 \sim 0.57$; FAM: $\mathrm{OR}=$ $0.40,95 \% \mathrm{CI}=0.02 \sim 0.78$; FAMTX: $\mathrm{OR}=0.50,95 \% \mathrm{CI}=$ $0.17 \sim 0.83$ ) (Figure 2a). The efficacies of fluorouracil and FAMTX chemotherapy regimens were relatively poorer in ORR of AGC patients (fluorouracil: $\mathrm{OR}=0.28,95 \% \mathrm{CI}=$ 


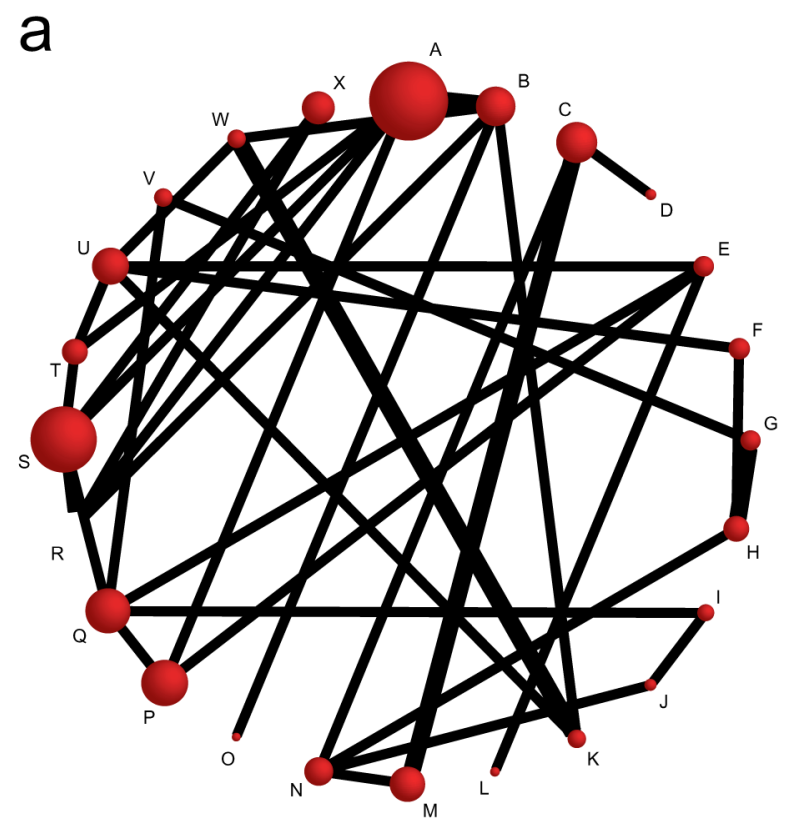

DCR

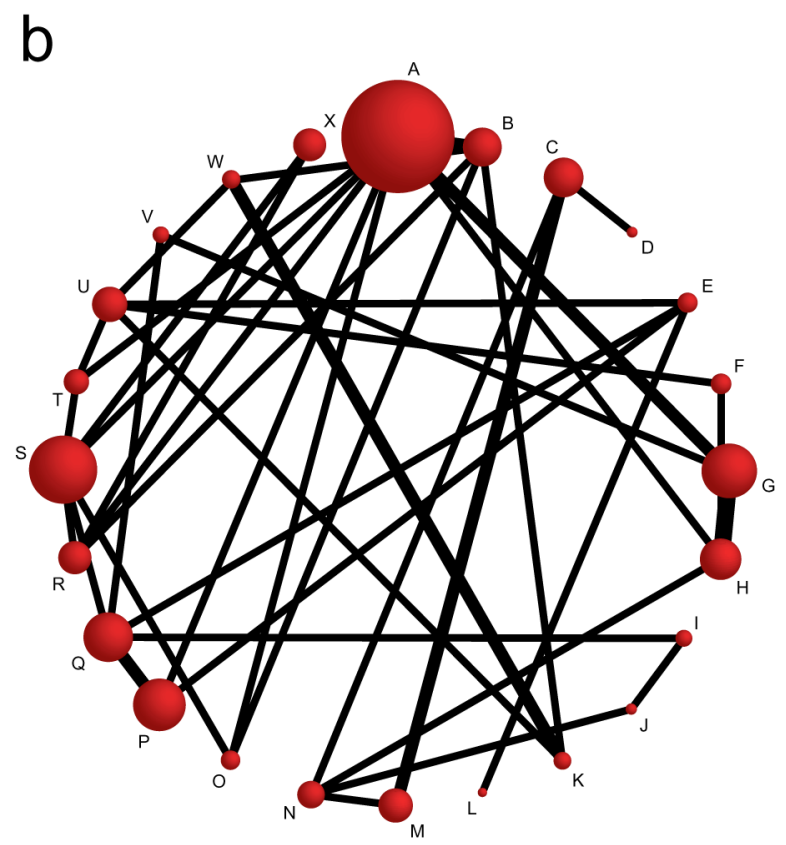

ORR

Figure 1: Network diagram for 24 kinds of chemotherapy regimens in terms of DCR and ORR (DCR $=$ disease control rate; ORR = overall response rate; A: cisplatin + fluorouracil; B: fluorouracil; C: S-1; D: capecitabine; E: docetaxel + cisplatin; F: irinotecan + cisplatin; G: cisplatin + capecitabine; H: S-1 + cisplatin; I: docetaxel + fluorouracil; J: paclitaxel + fluorouracil; K: fluorouracil + leucovorin; L: docetaxel + oxaliplatin; M: S-1 + irinotecan; N: S-1 + paclitaxel; O: etoposide + adriamycin + cisplatin; P: docetaxel + cisplatin + fluorouracil; Q: etoposide + cisplatin + fluorouracil; R: fluorouracil + adriamycin + mitomycin; S: fluorouracil + adriamycin + methotrexate; T: etoposide + leucovorin + fluorouracil; $U$ : fluorouracil + leucovorin + irinotecan; V: etoposide + cisplatin + capecitabine; W: fluorouracil + leucovorin + cisplatin; X: cisplatin + etoposide + leucovorin + fluorouracil; a: DCR; b: ORR). The size of the nodes is proportional to the number of studies that evaluate each intervention, and the thickness of the lines is proportional to the frequency of each comparison in the network. 
Table 1: The main baseline characteristics of included studies

\begin{tabular}{|c|c|c|c|c|c|c|c|c|c|c|}
\hline \multirow{2}{*}{ Author } & \multirow{2}{*}{ Year } & \multirow{2}{*}{ Country } & \multirow{2}{*}{ Ethnicity } & \multicolumn{3}{|c|}{ Number } & \multicolumn{3}{|c|}{ Interventions } & \multirow{2}{*}{ Outcomes } \\
\hline & & & & G1 & G2 & G3 & G1 & G2 & G3 & \\
\hline Wils JA & 1991 & Netherland & Caucasians & 79 & 81 & $\sim$ & $\mathrm{R}$ & $\mathrm{S}$ & & ORR; DCR \\
\hline Kelsen D & 1992 & USA & Caucasians & 30 & 30 & & $\mathrm{O}$ & S & & ORR \\
\hline Kim NK & 1993 & Korea & Asians & 55 & 54 & 57 & A & B & $\mathrm{R}$ & ORR; DCR \\
\hline Cocconi $\mathrm{G}$ & 1994 & Italy & Caucasians & 85 & 52 & $\sim$ & $X$ & $\mathrm{R}$ & & ORR; DCR \\
\hline Waters JS & 1999 & UK & Caucasians & 121 & 116 & $\sim$ & Q & S & & ORR; DCR \\
\hline Ohkuwa M & 2000 & Japan & Asians & 46 & 42 & & A & $\mathrm{O}$ & & ORR \\
\hline Vanhoefer U & 2000 & Netherland & Caucasians & 81 & 85 & 79 & A & $\mathrm{S}$ & $\mathrm{T}$ & ORR; DCR \\
\hline Bugat $R$ & 2003 & France & Caucasians & 74 & 72 & $\sim$ & $\mathrm{U}$ & $\mathrm{F}$ & & ORR; DCR \\
\hline Cocconi $\mathrm{G}$ & 2003 & Italy & Caucasians & 98 & 97 & $\sim$ & $\mathrm{X}$ & $\mathrm{S}$ & & ORR; DCR \\
\hline Ohtsu A & 2003 & Japan & Asians & 105 & 105 & $\sim$ & A & B & & ORR; DCR \\
\hline Bouche O & 2004 & France & Caucasians & 45 & 45 & 44 & K & $\mathrm{U}$ & W & ORR; DCR \\
\hline Moehler M & 2005 & Germany & Caucasians & 56 & 58 & $\sim$ & $\mathrm{U}$ & $\mathrm{T}$ & & ORR; DCR \\
\hline Thuss-Patience PC & 2005 & Germany & Caucasians & 45 & 45 & $\sim$ & Q & I & & ORR; DCR \\
\hline Park SH & 2006 & Korea & Asians & 39 & 38 & $\sim$ & $\mathrm{J}$ & I & & ORR; DCR \\
\hline Sadighi S & 2006 & Iran & Asians & 42 & 44 & & Q & $\mathrm{P}$ & & ORR \\
\hline Van CutsemE & 2006 & Belgium & Caucasians & 224 & 221 & & A & $\mathrm{P}$ & & ORR; DCR \\
\hline Lutz MP & 2007 & Germany & Caucasians & 33 & 48 & 46 & $\mathrm{~B}$ & K & $\mathrm{W}$ & ORR; DCR \\
\hline Roth AD & 2007 & Switzerland & Caucasians & 40 & 41 & 38 & Q & $\mathrm{P}$ & $\mathrm{E}$ & ORR; DCR \\
\hline Lee JL & 2008 & Korea & Asians & 45 & 46 & & $\mathrm{C}$ & $\mathrm{D}$ & & ORR; DCR \\
\hline Nakashima K & 2008 & Japan & Asians & 26 & 36 & & $\mathrm{~F}$ & $\mathrm{H}$ & & ORR; DCR \\
\hline Popov IP & 2008 & Serbia & Caucasians & 30 & 30 & & $\mathrm{~B}$ & $\mathrm{O}$ & & ORR; DCR \\
\hline Kang YK & 2009 & Korea & Asians & 137 & 139 & & A & $\mathrm{G}$ & & ORR \\
\hline Seol YM & 2009 & Korea & Asians & 32 & 40 & & $\mathrm{H}$ & G & & ORR; DCR \\
\hline Yun JA & 2009 & Korea & Asians & 44 & 45 & & $\mathrm{~V}$ & $\mathrm{G}$ & & ORR; DCR \\
\hline Lim LH & 2010 & Korea & Asians & 37 & 97 & 77 & $\mathrm{~A}$ & $\mathrm{H}$ & $\mathrm{G}$ & ORR \\
\hline Kim JA & 2011 & Korea & Asians & 28 & 30 & & $\mathrm{E}$ & $\mathrm{U}$ & & ORR; DCR \\
\hline Komatsu Y & 2011 & Japan & Asians & 47 & 48 & & $\mathrm{C}$ & $\mathrm{M}$ & & ORR; DCR \\
\hline Narahara H & 2011 & Japan & Asians & 93 & 94 & & $\mathrm{C}$ & $\mathrm{M}$ & & ORR; DCR \\
\hline Mochiki E & 2012 & Japan & Asians & 41 & 42 & & $\mathrm{H}$ & $\mathrm{N}$ & & ORR; DCR \\
\hline Nishikawa K & 2012 & Japan & Asians & 19 & 13 & & $\mathrm{~N}$ & $\mathrm{~J}$ & & ORR; DCR \\
\hline Ocvirk J & 2012 & Slovenia & Caucasians & 45 & 40 & & Q & $\mathrm{V}$ & & ORR; DCR \\
\hline Shitara K & 2013 & Japan & Asians & 37 & 20 & & $\mathrm{H}$ & $\mathrm{G}$ & & ORR; DCR \\
\hline Wang X & 2013 & China & Asians & 41 & 41 & & $\mathrm{C}$ & $\mathrm{N}$ & & ORR; DCR \\
\hline Kim YS & 2014 & Korea & Asians & 38 & 39 & & $\mathrm{E}$ & $\mathrm{L}$ & & ORR; DCR \\
\hline Sugimoto N & 2014 & Japan & Asians & 51 & 51 & & $\mathrm{~N}$ & M & & ORR; DCR \\
\hline
\end{tabular}

Note: G:Group; DCR = disease control rate; ORR = overall response rate; A: cisplatin + fluorouracil; B: fluorouracil; C: S-1; D: capecitabine; E: docetaxel + cisplatin; F: irinotecan + cisplatin; G: cisplatin + capecitabine; H: S-1 + cisplatin; I: docetaxel + fluorouracil; J: paclitaxel + fluorouracil; K: fluorouracil + leucovorin; L: docetaxel + oxaliplatin; M: S-1 + irinotecan; N: S-1 + paclitaxel; O: etoposide + adriamycin + cisplatin; P: docetaxel + cisplatin + fluorouracil; Q: etoposide + cisplatin + fluorouracil; R: fluorouracil + adriamycin + mitomycin; S: fluorouracil + adriamycin + methotrexate; T: etoposide + leucovorin + fluorouracil; U: fluorouracil + leucovorin + irinotecan; V: etoposide + cisplatin + capecitabine; W:fluorouracil + leucovorin + cisplatin; X:cisplatin + etoposide + leucovorin + fluorouracil. 


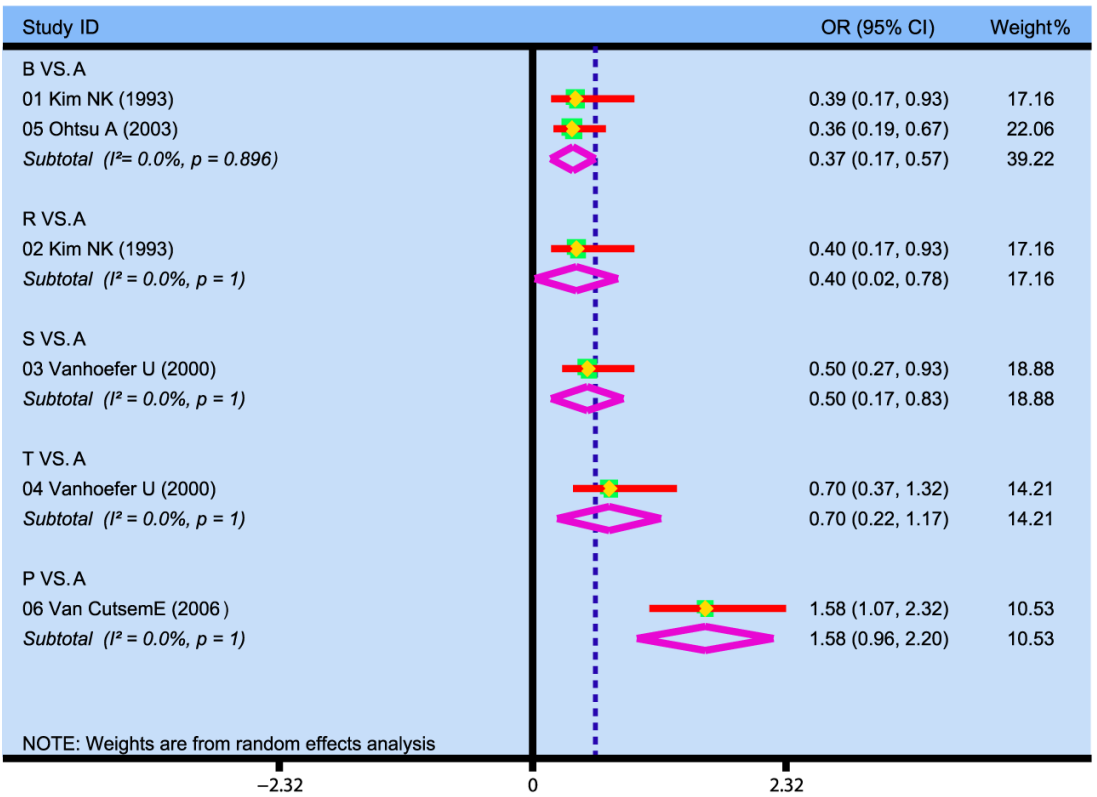

b

\begin{tabular}{|c|c|c|}
\hline Study ID & OR $(95 \% \mathrm{Cl})$ & Weight $\%$ \\
\hline \multicolumn{3}{|l|}{ B VS.A } \\
\hline 01 Kim NK (1993) & $0.34(0.15,0.76)$ & 15.98 \\
\hline 06 Ohtsu A (2003) & $0.25(0.12,0.51)$ & 17.59 \\
\hline Subtotal $\left(I^{2}=0.0 \%, p=0.626\right)$ & $0.28(0.11,0.44)$ & 33.58 \\
\hline \multicolumn{3}{|l|}{ R VS.A } \\
\hline O2 Kim NK (1993) & $0.31(0.14,0.70)$ & 16.38 \\
\hline Subtotal $\left(l^{2}=0.0 \%, p=1\right)$ & $0.31(0.03,0.59)$ & 16.38 \\
\hline \multicolumn{3}{|l|}{ OVS.A } \\
\hline 03 Ohkuwa M (2000) & $1.57(0.68,3.65)$ & 3.55 \\
\hline Subtotal $\left(1^{2}=0.0 \%, p=1\right)$ & $1.57(0.09,3.06)$ & 3.55 \\
\hline \multicolumn{3}{|l|}{ S VS.A } \\
\hline 04 Vanhoefer U (2000) & $0.54(0.23,1.28)$ & 12.27 \\
\hline Subtotal $\left(I^{2}=0.0 \%, p=1\right)$ & $0.54(0.02,1.06)$ & 12.27 \\
\hline \multicolumn{3}{|l|}{ T VS.A } \\
\hline 05 Vanhoefer U (2000) & $0.39(0.15,1.02)$ & 13.78 \\
\hline Subtotal $\left(l^{2}=0.0 \%, p=1\right)$ & $0.39(-0.04,0.82)$ & 13.78 \\
\hline \multicolumn{3}{|l|}{ P VS.A } \\
\hline 07 Van CutsemE (2006) & $1.70(1.13,2.55)$ & 9.50 \\
\hline Subtotal $\left(I^{2}=0.0 \%, p=1\right)$ & $1.70(0.99,2.41)$ & 9.50 \\
\hline \multicolumn{3}{|l|}{ GVS.A } \\
\hline 08 Kang YK (2009) & $1.80(1.11,2.94)$ & 7.15 \\
\hline $10 \mathrm{Lim}$ doH (2010) & $2.10(0.87,5.05)$ & 1.97 \\
\hline Subtotal $\left(l^{2}=0.0 \%, p=1\right)$ & $1.85(1.01,2.69)$ & 9.12 \\
\hline \multicolumn{3}{|l|}{ HVS.A } \\
\hline $09 \mathrm{Lim}$ doH (2010) & $2.28(0.97,5.34)$ & 1.82 \\
\hline Subtotal $\left(l^{2}=0.0 \%, p=1\right)$ & $2.28(0.09,4.47)$ & 1.82 \\
\hline
\end{tabular}

Figure 2: Forest plots of traditional meta-analysis for 24 kinds of chemotherapy regimens in terms of DCR and ORR $(\mathrm{DCR}=$ disease control rate; ORR = overall response rate; A: cisplatin + fluorouracil; B: fluorouracil; C: S-1; D: capecitabine; E: docetaxel + cisplatin; F: irinotecan + cisplatin; G: cisplatin + capecitabine; H: S-1 + cisplatin; I: docetaxel + fluorouracil; J: paclitaxel + fluorouracil; K: fluorouracil + leucovorin; L: docetaxel + oxaliplatin; M: S-1 + irinotecan; N: S-1 + paclitaxel; O: etoposide + adriamycin + cisplatin; P: docetaxel + cisplatin + fluorouracil; Q: etoposide + cisplatin + fluorouracil; R: fluorouracil + adriamycin + mitomycin; S: fluorouracil + adriamycin + methotrexate; T: etoposide + leucovorin + fluorouracil; U: fluorouracil + leucovorine + irinotecan; V: etoposide + cisplatin + capecitabine; W: fluorouracil + leucovorin + cisplatin; X: cisplatin + etoposide + leucovorin + fluorouracil; a: DCR; b: ORR). 
0.11 0.44; FAM: $\mathrm{OR}=0.31,95 \% \mathrm{CI}=0.03 \sim 0.59$ ), while CX chemotherapy regimens had better efficacy for AGC $(\mathrm{OR}=1.85,95 \% \mathrm{CI}=1.01 \sim 2.69)$ (Figure 2b).

\section{Pooled results of network meta-analysis}

\section{Inconsistency test of DCR and ORR in included studies}

Design-by-treatment interaction model was used for the inconsistency test of DCR and ORR, the Wald test showed that all direct evidence and indirect evidence were consistent, and the fixed effect model was adopted (DCR: $P=0.7428$, ORR: $P=0.2420)$.

\section{Comparisons of DCR in different chemotherapy regimens}

Totally 30 studies reported the differences of efficacy of DCR in AGC patients treated with twenty-four chemotherapy regimens. Network meta-analysis showed that as for single drug regimen, there was no significant difference for DCR in fluorouracil, S-1, and capecitabine chemotherapy regimens.

As for multi-drug combination regimen, AGC patients treated with CX, DCF and ECX chemotherapy regimens had better DCR when compared with $\mathrm{CF}$ chemotherapy regimen $(\mathrm{CX}: \mathrm{OR}=4.27,95 \% \mathrm{CI}=$ 1.05 17.00; DCF : OR $=1.86,95 \% \mathrm{CI}=1.05 \sim 3.84$; ECX: $\mathrm{OR}=4.83,95 \% \mathrm{CI}=1.39 \sim 16.62$ ), while the DCR of FAM chemotherapy regimens were relatively poorer $(\mathrm{OR}=$ $0.25,95 \% \mathrm{CI}=0.13 \sim 0.52$ ) (Figure 3a).

Compared with DC chemotherapy regimen, the DCR of ECX chemotherapy regimen was relatively good $(\mathrm{OR}=4.03,95 \% \mathrm{CI}=1.04 \sim 16.78)$, while the DCR of FAM chemotherapy regimen was relatively poorer (OR $=0.22,95 \% \mathrm{CI}=0.07 \sim 0.68)$. The DCR of CX, S-1P and ECX chemotherapy regimens were relatively better than $\mathrm{CI}$ chemotherapy regimen $(\mathrm{CX}: \mathrm{OR}=5.59,95 \% \mathrm{CI}$ $=1.40 \sim 23.76$; $\mathrm{S}-1 \mathrm{P}: \mathrm{OR}=6.81,95 \% \mathrm{CI}=1.27 \sim 42.87$; ECX: OR $=6.40,95 \% \mathrm{CI}=1.50-26.1)$. The DCR of CF, CI, PF, FL, FAM, FAMTX, ELF and CELF chemotherapy regimens were relatively poorer than $\mathrm{CX}$ chemotherapy regimen $(\mathrm{CF}$ : $\mathrm{OR}=0.23,95 \% \mathrm{CI}=0.06 \sim 0.95 ; \mathrm{CI}$ : OR $=0.18,95 \% \mathrm{CI}=0.04 \sim 0.71 ; \mathrm{PF}: \mathrm{OR}=0.17,95 \% \mathrm{CI}=$ $0.02 \sim 0.89$; FL: OR $=0.19,95 \% \mathrm{CI}=0.04 \sim 0.87$; FAM: OR $=0.06,95 \% \mathrm{CI}=0.01 \sim 0.26$; FAMTX: OR $=0.14,95 \% \mathrm{CI}$ $=0.04 \sim 0.55$; ELF: $\mathrm{OR}=0.16,95 \% \mathrm{CI}=0.04 \sim 0.67$; CELF: $\mathrm{OR}=0.19,95 \% \mathrm{CI}=0.04 \sim 0.90)$.

Compared with S-1C chemotherapy regimen, the DCR of FAM, FAMTX and ELF chemotherapy regimens were relatively poorer $(\mathrm{FAM}$ : $\mathrm{OR}=0.08,95 \% \mathrm{CI}=$ 0.02 0.41; FAMTX: $\mathrm{OR}=0.19,95 \% \mathrm{CI}=0.05 \sim 0.85$; ELF: $\mathrm{OR}=0.22,95 \% \mathrm{CI}=0.05 \sim 0.96)$. The DCR of ECX chemotherapy regimen was relatively better than DF chemotherapy regimen $(\mathrm{OR}=4.54,95 \% \mathrm{CI}=1.27 \sim 20.81)$.
The DCR of CX, S-1P and ECX chemotherapy regimens were relatively better than $\mathrm{PF}$ chemotherapy regimen $(\mathrm{CX}$ : $\mathrm{OR}=5.90,95 \% \mathrm{CI}=1.12 \sim 43.52 ; \mathrm{S}-1 \mathrm{P}: \mathrm{OR}=6.73,95 \% \mathrm{CI}$ $=1.09 \sim 63.93$; $\mathrm{ECX}: \mathrm{OR}=6.22,95 \% \mathrm{CI}=1.31 \sim 41.92$ ). Compared with FL chemotherapy regimen, the DCR of CX, S-1P, ECX and FLC chemotherapy regimens were relatively better $(\mathrm{CX}: \mathrm{OR}=5.21,95 \% \mathrm{CI}=1.15 \sim 25.77$; $\mathrm{S}-1 \mathrm{P}: \mathrm{OR}=6.27,95 \% \mathrm{CI}=1.02 \sim 45.52 ; \mathrm{ECX}: \mathrm{OR}=$ $5.68,95 \% \mathrm{CI}=1.43 \sim 25.94 ; \mathrm{FLC}: \mathrm{OR}=2.41,95 \% \mathrm{CI}$ $=1.12 \sim 5.28$ ), while the DCR of FAM chemotherapy regimen was relatively poorer $(\mathrm{OR}=0.31,95 \% \mathrm{CI}=$ $0.10 \sim 0.87$ ).

The DCR of FAM chemotherapy regimen was relatively poorer than DO chemotherapy regimen (OR $=0.12,95 \% \mathrm{CI}=0.02 \sim 0.60)$; and the DCR of FAM and FAMTX chemotherapy regimens were relatively poorer than S-1I chemotherapy regimen (FAM: OR = $0.06,95 \% \mathrm{CI}=0.01 \sim 0.41$; FAMTX: OR $=0.14,95 \% \mathrm{CI}$ $=0.02 \sim 0.91)$. Compared with S-1P chemotherapy regimen, the DCR of CI, PF, FL, FAM, FAMTX and ELF chemotherapy regimens were relatively poorer $(\mathrm{CI}$ : $\mathrm{OR}$ $=0.15,95 \% \mathrm{CI}=0.02 \sim 0.79$; $\mathrm{PF}: \mathrm{OR}=0.15,95 \% \mathrm{CI}=$ 0.02 0.92; FL: OR $=0.16,95 \% \mathrm{CI}=0.02 \sim 0.98$; FAM: OR $=0.05,95 \% \mathrm{CI}=0.01 \sim 0.30$; FAMTX: OR $=0.11,95 \% \mathrm{CI}$ $=0.02 \sim 0.64$; ELF: $\mathrm{OR}=0.13,95 \% \mathrm{CI}=0.02 \sim 0.77$ ). The DCR of FAM chemotherapy regimen was relatively poorer than EAC chemotherapy regimen $(\mathrm{OR}=0.18$, $95 \% \mathrm{CI}=0.04 \sim 0.84)$. The DCR of CF, FAM, FAMTX and ELF chemotherapy regimens were relatively poorer than DCF chemotherapy regimen $(\mathrm{CF}: \mathrm{OR}=0.54,95 \% \mathrm{CI}$ $=0.26 \sim 0.95$; FAM: $\mathrm{OR}=0.13,95 \% \mathrm{CI}=0.05 \sim 0.31$; FAMTX: OR $=0.31,95 \% \mathrm{CI}=0.14 \sim 0.67$; ELF: OR $=$ $0.35,95 \% \mathrm{CI}=0.14 \sim 0.83)$.

Compared with ECF chemotherapy regimen, the DCR of FAM, FAMTX and ELF chemotherapy regimens were relatively poorer (FAM: OR $=0.14$, $95 \% \mathrm{CI}=0.06 \sim 0.35$; FAMTX: OR $=0.34,95 \% \mathrm{CI}=$ $0.17 \sim 0.67$; ELF: $\mathrm{OR}=0.37,95 \% \mathrm{CI}=0.15 \sim 0.93)$. Compared with FLI chemotherapy regimen, the DCR of ECX chemotherapy regimen was relatively better $(\mathrm{OR}=3.82,95 \% \mathrm{CI}=1.06 \sim 14.81)$, while the DCR of FAM chemotherapy regimen was relatively poorer (OR $=0.20,95 \% \mathrm{CI}=0.08 \sim 0.54)$. The DCR of FL, FAM and FAMTX chemotherapy regimens were relatively poorer than FLC chemotherapy regimen (FL: OR = $0.41,95 \% \mathrm{CI}=0.19 \sim 0.89$; FAM: $\mathrm{OR}=0.13,95 \% \mathrm{CI}=$ 0.05 0.38; FAMTX: OR $=0.29,95 \% \mathrm{CI}=0.10 \sim 0.88)$. The comparisons of DCR in different chemotherapy regimens are showed in Supplementary Table 1.

\section{Comparisons of ORR in different chemotherapy regimens}

The differences in the ORR of twenty-four chemotherapy regimens in the treatment of AGC were reported in 35 studies. Network meta-analysis revealed 


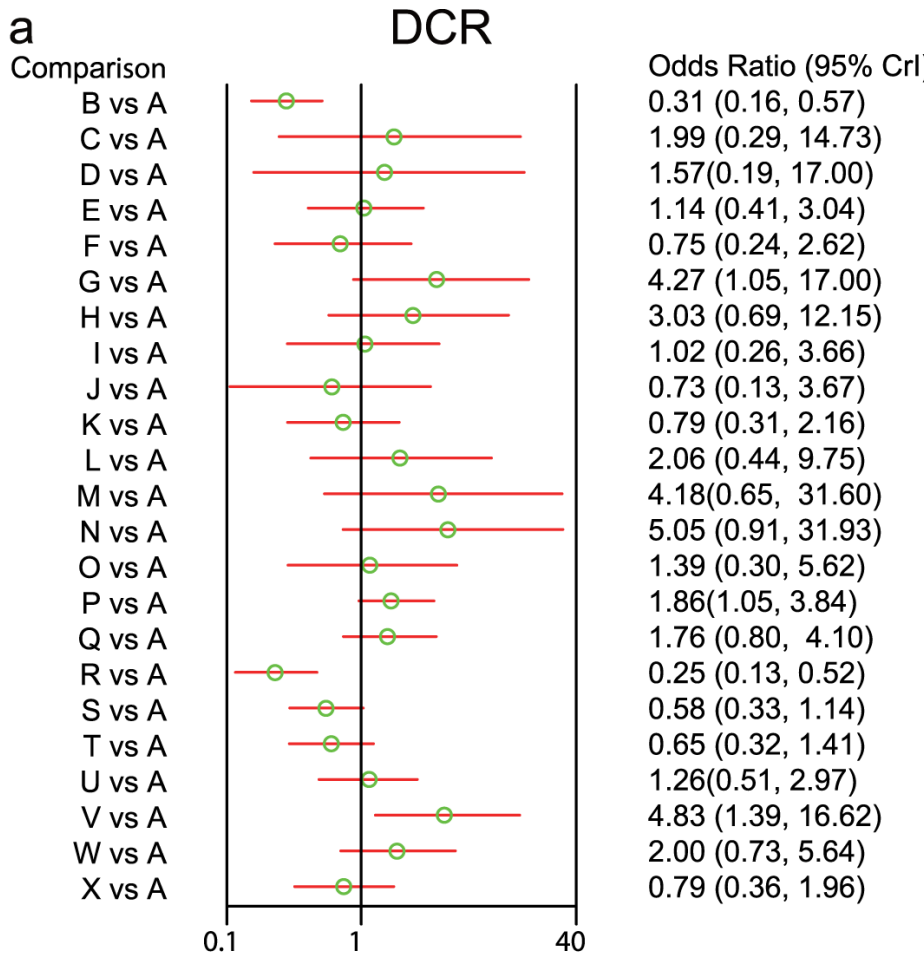

b

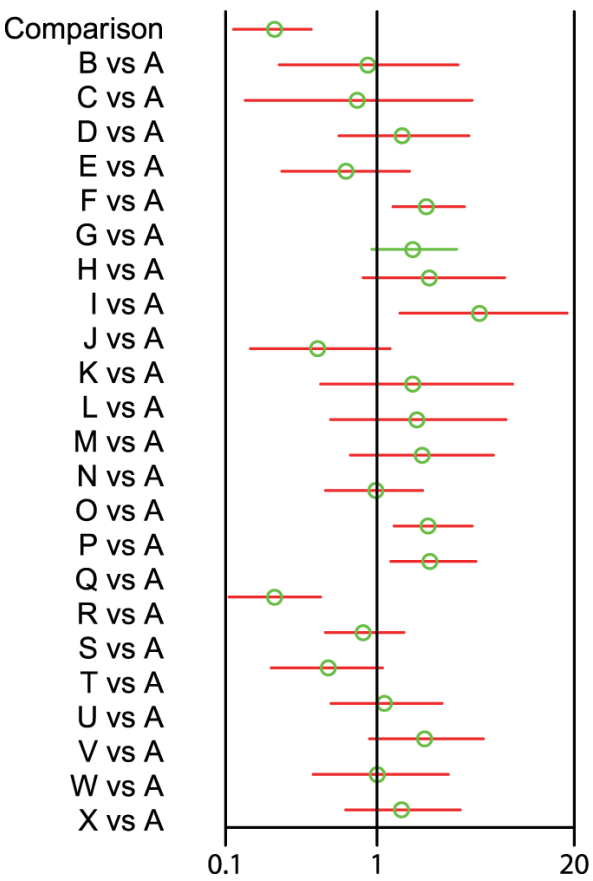

Odds Ratio (95\% Crl)

$0.21(0.11,0.38)$

$0.86(0.21,3.46)$

$0.75(0.12,4.50)$

$1.51(0.57,4.01)$

$0.63(0.22,1.61)$

$2.18(1.24,3.86)$

$1.96(0.98,3.82)$

$2.78(0.89,9.0)$

$4.53(1.34,18.38)$

$0.41(0.14,1.21)$

$1.78(0.41,8.13)$

$1.77(0.46,7.43)$

$1.95(0.65,6.01)$

$0.95(0.46,2.09)$

$2.25(1.28,4.49)$

$2.27(1.24,4.25)$

$0.21(0.10,0.43)$

$0.81(0.46,1.56)$

$0.48(0.18,1.13)$

$1.16(0.48,2.52)$

$2.13(0.90,5.16)$

$1.04(0.38,2.95)$

$1.47(0.59,3.62)$

Figure 3: Forest plots of relationship for 24 kinds of chemotherapy regimens in terms of DCR and ORR (DCR = disease control rate; ORR = overall response rate; A: cisplatin + fluorouracil; B: fluorouracil; C: S-1; D: capecitabine; E: docetaxel + cisplatin; F: irinotecan + cisplatin; G: cisplatin + capecitabine; H: S-1 + cisplatin; I: docetaxel + fluorouracil; J: paclitaxel + fluorouracil; K: fluorouracil + leucovorin; L: docetaxel + oxaliplatin; M: S-1 + irinotecan; N: S-1 + paclitaxel; O: etoposide + adriamycin + cisplatin; P: docetaxel + cisplatin + fluorouracil; Q: etoposide + cisplatin + fluorouracil; R: fluorouracil + adriamycin + mitomycin; S: fluorouracil + adriamycin + methotrexate; T: etoposide + leucovorin + fluorouracil; U: fluorouracil + leucovorine + irinotecan; V: etoposide + cisplatin + capecitabine; W: fluorouracil + leucovorin + cisplatin; X: cisplatin + etoposide + leucovorin + fluorouracil; a: DCR; b: ORR). 
that as for single drug regimen, there was no significant difference for ORR in fluorouracil, S-1, and capecitabine chemotherapy regimens. As for multi-drug combination regimen, AGC patients treated with $\mathrm{CX}, \mathrm{PF}, \mathrm{DCF}$ and ECF chemotherapy regimens had better efficacy when compared with $\mathrm{CF}$ chemotherapy regimen (CX: OR $=2.18,95 \% \mathrm{CI}=1.24 \sim 3.86 ; \mathrm{PF}: \mathrm{OR}=4.53,95 \% \mathrm{CI}$ $=1.34 \sim 18.38 ;$ DCF: $\mathrm{OR}=2.25,95 \% \mathrm{CI}=1.28-4.49$; ECF: $\mathrm{OR}=2.27,95 \% \mathrm{CI}=1.24-4.50)$, while FAM chemotherapy regimen had poorer efficacy (FAM: OR = $0.21,95 \% \mathrm{CI}=0.10 \sim 0.43)$ (Figure $3 \mathrm{~b}$ )

The ORR of FAM chemotherapy regimen was relatively poorer than DC chemotherapy regimen $(\mathrm{OR}=0.14,95 \% \mathrm{CI}=0.04 \sim 0.44)$. Compared with $\mathrm{CI}$ chemotherapy regimen, the ORR of CX, S-1C, DF, PF, DCF, ECF and ECX chemotherapy regimen was relatively better (CX: OR $=3.49,95 \% \mathrm{CI}=1.29 \sim 10.46$; S-1C: OR $=3.18,95 \% \mathrm{CI}=1.20 \sim 8.83$; DF: $\mathrm{OR}=4.44,95 \% \mathrm{CI}=$ 1.13 20.04; PF: $\mathrm{OR}=7.30,95 \% \mathrm{CI}=1.69 \sim 38.97$; DCF: $\mathrm{OR}=3.59,95 \% \mathrm{CI}=1.26 \sim 12.18 ; \mathrm{ECF}: \mathrm{OR}=3.64,95 \% \mathrm{CI}$ $=1.28-11.81$; $\mathrm{ECX}: \mathrm{OR}=3.34,95 \% \mathrm{CI}=1.01-12.46)$. Compared with CX chemotherapy regimen, the ORR of CF, CI, FL, FAM, FAMTX and ELF chemotherapy regimen was relatively poorer $(\mathrm{CF}: \mathrm{OR}=0.46,95 \% \mathrm{CI}=$ $0.26 \sim 0.81$; CI: OR $=0.29,95 \% \mathrm{CI}=0.10 \sim 0.78$; FL: OR $=0.19,95 \% \mathrm{CI}=0.06 \sim 0.61 ; \mathrm{FAM}: \mathrm{OR}=0.10,95 \% \mathrm{CI}$ $=0.04 \sim 0.23$; FAMTX: $\mathrm{OR}=0.38,95 \% \mathrm{CI}=0.18 \sim 0.85$; $\mathrm{ELF}: \mathrm{OR}=0.22,95 \% \mathrm{CI}=0.07 \sim 0.59$ ).

The ORR of CI, FL, FAM and ELF chemotherapy regimens were relatively poorer than S-1C chemotherapy regimen $(\mathrm{CI}: \mathrm{OR}=0.31,95 \% \mathrm{CI}=0.11 \sim 0.83$; $\mathrm{FL}: \mathrm{OR}=$ $0.21,95 \% \mathrm{CI}=0.07 \sim 0.68 ; \mathrm{FAM}: \mathrm{OR}=0.11,95 \% \mathrm{CI}=$ $0.04 \sim 0.28$; ELF: $\mathrm{OR}=0.24,95 \% \mathrm{CI}=0.08 \sim 0.70)$. The ORR of CI, FL, FAM, FAMTX and ELF chemotherapy regimens were relatively poorer than DF chemotherapy regimen $(\mathrm{CI}$ : $\mathrm{OR}=0.23,95 \% \mathrm{CI}=0.05 \sim 0.88$; FL: OR $=0.15,95 \% \mathrm{CI}=0.03 \sim 0.61$; FAM: OR $=0.08,95 \% \mathrm{CI}$ $=0.02 \sim 0.25$; FAMTX: $\mathrm{OR}=0.30,95 \% \mathrm{CI}=0.09 \sim 0.91$; ELF: $\mathrm{OR}=0.17,95 \% \mathrm{CI}=0.04 \sim 0.65)$. Compared with PF chemotherapy regimen, the ORR of CF, CI, FL, EAC, FAM, FAMT and ELF chemotherapy regimen were relatively poorer $(\mathrm{CF}: \mathrm{OR}=0.22,95 \% \mathrm{CI}=0.05 \sim 0.75$; $\mathrm{CI}$ : $\mathrm{OR}=0.14,95 \% \mathrm{CI}=0.03 \sim 0.59 ; \mathrm{FL}: \mathrm{OR}=0.09,95 \% \mathrm{CI}$ $=0.02 \sim 0.43$; $\mathrm{EAC}: \mathrm{OR}=0.21,95 \% \mathrm{CI}=0.04 \sim 0.96$; FAM: OR $=0.05,95 \% \mathrm{CI}=0.01 \sim 0.18$; FAMTX: OR $=$ $0.18,95 \% \mathrm{CI}=0.04 \sim 0.66 ; \mathrm{ELF}: \mathrm{OR}=0.11,95 \% \mathrm{CI}=$ $0.02 \sim 0.44)$.

Compared with FL chemotherapy regimen, the ORR of CX, S-1C, DF, PF, S-1P, DCF, ECF, FLI, ECX and FLC chemotherapy regimens were relatively better $(\mathrm{CX}: \mathrm{OR}=$ $5.34,95 \% \mathrm{CI}=1.65 \sim 17.11 ; \mathrm{S}-1 \mathrm{C}: \mathrm{OR}=4.78,95 \% \mathrm{CI}=$ $1.47 \sim 15.37$; DF: $\mathrm{OR}=6.74,95 \% \mathrm{CI}=1.65 \sim 29.06$; PF: OR $=10.94,95 \% \mathrm{CI}=2.33 \sim 60.45 ; \mathrm{S}-1 \mathrm{P}: \mathrm{OR}=4.84,95 \% \mathrm{CI}=$ 1.01 20.27; DCF: $\mathrm{OR}=5.42,95 \% \mathrm{CI}=1.85 \sim 18.24$; ECF: $\mathrm{OR}=5.55,95 \% \mathrm{CI}=1.84 \sim 17.86$; FLI: $\mathrm{OR}=2.77,95 \% \mathrm{CI}$
$=1.08 \sim 6.94 ; \mathrm{ECX}: \mathrm{OR}=5.16,95 \% \mathrm{CI}=1.39 \sim 19.25$; FLC: $\mathrm{OR}=2.53,95 \% \mathrm{CI}=1.15 \sim 5.47)$. The ORR of FAM chemotherapy regimen was relatively poorer than DO chemotherapy regimen $(\mathrm{OR}=0.12,95 \% \mathrm{CI}=0.02 \sim 0.57)$. The ORR of FAM chemotherapy regimen was also poorer than $\mathrm{S}-1 \mathrm{I}$ chemotherapy regimen $(\mathrm{OR}=0.12$, $95 \% \mathrm{CI}=0.03 \sim 0.55)$. Compared with S-1P chemotherapy regimen, the ORR of FL, FAM and ELF chemotherapy regimens were relatively poorer $(\mathrm{FL}: \mathrm{OR}=0.21,95 \% \mathrm{CI}$ $=0.05 \sim 0.99$; FAM: $\mathrm{OR}=0.11,95 \% \mathrm{CI}=0.03 \sim 0.40$; ELF: $\mathrm{OR}=0.25,95 \% \mathrm{CI}=0.06 \sim 0.95)$. Compared with EAC chemotherapy regimen, the ORR of PF chemotherapy regimen was relatively better $(\mathrm{OR}=4.75,95 \% \mathrm{CI}=$ 1.04 24.22), while the ORR of FAM chemotherapy regimen was relatively poorer $(\mathrm{OR}=0.22,95 \% \mathrm{CI}=$ $0.08 \sim 0.58)$. The ORR of CF, CI, FL, FAM, FAMTX and ELF chemotherapy regimens were relatively poorer than DCF chemotherapy regimen $(\mathrm{CF}: \mathrm{OR}=0.44,95 \% \mathrm{CI}=$ $0.22 \sim 0.78$; $\mathrm{CI}: \mathrm{OR}=0.28,95 \% \mathrm{CI}=0.08 \sim 0.79$; FL: OR $=0.18,95 \% \mathrm{CI}=0.05 \sim 0.54$; FAM: OR $=0.09,95 \% \mathrm{CI}$ $=0.04 \sim 0.22$; FAMTX: OR $=0.36,95 \% \mathrm{CI}=0.17 \sim 0.76$; $\mathrm{ELF}: \mathrm{OR}=0.22,95 \% \mathrm{CI}=0.07 \sim 0.55)$.

The ORR of CF, CI, FL FAM, FAMTX and ELF chemotherapy regimens were relatively poorer than ECF chemotherapy regimen $(\mathrm{CF}: \mathrm{OR}=0.44,95 \% \mathrm{CI}=$ $0.22 \sim 0.81$; $\mathrm{CI}: \mathrm{OR}=0.27,95 \% \mathrm{CI}=0.08 \sim 0.78$; FL: OR $=0.18,95 \% \mathrm{CI}=0.06 \sim 0.54$; FAM: OR $=0.09,95 \% \mathrm{CI}$ $=0.04 \sim 0.21$; FAMTX: OR $=0.35,95 \% \mathrm{CI}=0.19 \sim 0.68$; ELF: $\mathrm{OR}=0.21,95 \% \mathrm{CI}=0.07 \sim 0.53)$. Compared with FLI chemotherapy regimen, the ORR of FL, FAM and ELF chemotherapy regimens were relatively poorer (FL: $\mathrm{OR}=0.36,95 \% \mathrm{CI}=0.14 \sim 0.93$; FAM: $\mathrm{OR}=0.19,95 \% \mathrm{CI}$ $=0.07 \sim 0.53$; ELF: OR $=0.41,95 \% \mathrm{CI}=0.19 \sim 0.97)$. Compared with FLC chemotherapy regimen, the DCR of FL and FAM chemotherapy regimens were relatively poorer $(\mathrm{FL}$ : $\mathrm{OR}=0.40,95 \% \mathrm{CI}=0.18 \sim 0.87$; FAM: $\mathrm{OR}=$ $0.21,95 \% \mathrm{CI}=0.06 \sim 0.65)$. The comparisons of ORR in different chemotherapy regimens are displayed in detail in Supplementary Table 2.

\section{Surface under the cumulative ranking curves (SUCRA) curves for short-term efficacy of twenty-four chemotherapy regimens in the treatment of advanced gastric cancer}

As shown in Table 2, in the outcome of DCR, the chemotherapy regimens of S-1 and capecitabine was better than fluorouracil in terms of single drug regimen, while S-1P chemotherapy regimen had better efficacy for AGC patients with respect to multi-drug combination regimen. In the outcome of ORR, the chemotherapy regimens of S-1 and capecitabine was better than fluorouracil in terms of single drug regimen, while PF chemotherapy regimen had better efficacy for AGC patients with respect to multidrug combination regimen. 
Table 2: SUCRA values of twenty four treatment modalities under two endpoint outcomes

\begin{tabular}{|c|c|c|}
\hline \multirow{2}{*}{ Treatment } & \multicolumn{2}{|c|}{ SUCRA values } \\
\hline & DCR & ORR \\
\hline A & 0.399 & 0.393 \\
\hline B & 0.051 & 0.033 \\
\hline $\mathrm{C}$ & 0.619 & 0.359 \\
\hline $\mathrm{D}$ & 0.546 & 0.330 \\
\hline E & 0.450 & 0.577 \\
\hline $\mathrm{F}$ & 0.277 & 0.246 \\
\hline G & 0.859 & 0.763 \\
\hline $\mathrm{H}$ & 0.756 & 0.712 \\
\hline I & 0.403 & 0.820 \\
\hline $\mathrm{J}$ & 0.283 & 0.934 \\
\hline $\mathrm{K}$ & 0.307 & 0.137 \\
\hline $\mathrm{L}$ & 0.655 & 0.655 \\
\hline M & 0.848 & 0.666 \\
\hline $\mathrm{N}$ & 0.900 & 0.705 \\
\hline $\mathrm{O}$ & 0.530 & 0.385 \\
\hline $\mathrm{P}$ & 0.659 & 0.767 \\
\hline Q & 0.616 & 0.780 \\
\hline $\mathrm{R}$ & 0.027 & 0.040 \\
\hline S & 0.184 & 0.317 \\
\hline $\mathrm{T}$ & 0.225 & 0.161 \\
\hline $\mathrm{U}$ & 0.496 & 0.477 \\
\hline $\mathrm{V}$ & 0.896 & 0.740 \\
\hline $\mathrm{W}$ & 0.674 & 0.437 \\
\hline $\mathrm{X}$ & 0.315 & 0.577 \\
\hline
\end{tabular}

Notes: $\mathrm{DCR}=$ disease control rate; ORR = overall response rate; A: cisplatin + fluorouracil; B: fluorouracil; C: S-1; D: capecitabine; E: docetaxel + cisplatin; F: irinotecan + cisplatin; G: cisplatin + capecitabine; H: S-1 + cisplatin; I: docetaxel + fluorouracil; J: paclitaxel + fluorouracil; K: fluorouracil + leucovorin; L: docetaxel + oxaliplatin; M: S-1 + irinotecan; N: S-1 + paclitaxel; O: etoposide + adriamycin + cisplatin; P: docetaxel + cisplatin + fluorouracil; Q: etoposide + cisplatin + fluorouracil; R: fluorouracil + adriamycin + mitomycin; S: fluorouracil + adriamycin + methotrexate; T: etoposide + leucovorin + fluorouracil; U: fluorouracil + leucovorin + irinotecan; V: etoposide + cisplatin + capecitabine; W: fluorouracil + leucovorin + cisplatin; X: cisplatin + etoposide + leucovorin + fluorouracil.

\section{Cluster analysis for short-term efficacy of twenty-four chemotherapy regimens in the treatment of advanced gastric cancer}

Cluster analysis was conducted for the SUCRA values of twenty-four chemotherapy regimens in the outcomes of DCR and ORR. The results of cluster analysis demonstrated that AGC patients treated with CX, ECX, S-1P and S-1I chemotherapy regimens had better efficacy
(Figure 4). The SUCRA plots of CX, ECX, S-1P and S-1I chemotherapy regimens under different outcomes are showed in Figure 5a-5d.

\section{DISCUSSION}

The network meta-analysis results revealed that there was no significant difference for DCR and ORR in the chemotherapy regimens of fluorouracil, S-1 and 
capecitabine in terms of single drug regimen, while the results of SUCRA showed that the chemotherapy regimens of S-1 and capecitabine were better than fluorouracil. Various chemotherapeutic agents have been used for improving response rate (RR), progression-free survival (PFS), overall survival (OS), and quality of life in patients with AGC [51]. Fluorouracil-based chemotherapy is commonly used for AGC, which has been suggested to have a survival benefit in comparison with the best supportive care [31]. Study has shown that without the inconvenience and complications associated with central venous catheters for fluorouracil, capecitabine maintains a constant level of 5-FU, which is therefore expected to have improved efficacy and tolerability when compared with protracted infusion 5-FU [52]. In the 1990s, S-1, as an oral derivative of 5-FU, was produced for the treatment of GC. As a single agent, S-1 was expected to have a high response rate of $46 \%$, which rapidly established itself as a standard treatment for GC in Japan and was also used widely in clinical practice [32]. The presence of these new generation agents could play important roles in improving patient outcomes, and presenting the access to establish novel chemotherapeutic strategies and personalized medicine, which would help for each individual to select the optimal therapy and dose based on both the tumor and the patient [53]. In consideration of the ORR, OS as well as safety results, J-L Lee in his study provided evidence that patients with AGC could benefit from capecitabine or S-1 monotherapy with minimal adverse events [54]. A subset analysis of the FLAGS trial demonstrated that S-1 seemed to have better efficacy than 5-FU in diffuse type GC [55]. Both capecitabine and S-1 are more tolerable than 5-FU, and has been shown to present antitumor activity against AGC [56]. To some extent, single agent chemotherapy could be regarded as a good and safe firstline treatment for $\mathrm{AGC}$, and it can avoid the compounding effects of other agents when combination therapy is used.

The network meta-analysis clearly shows that multi-drug combination chemotherapy regimens based on capecitabine and S-1 might be the best chemotherapy regimen for AGC. Various attempts have been made since the 1970s, in order to improve the results of chemotherapy through using multi-drug combination chemotherapy regimens. Randomized trials that making comparisons between monotherapy with combination regimens have consistently indicated increased response

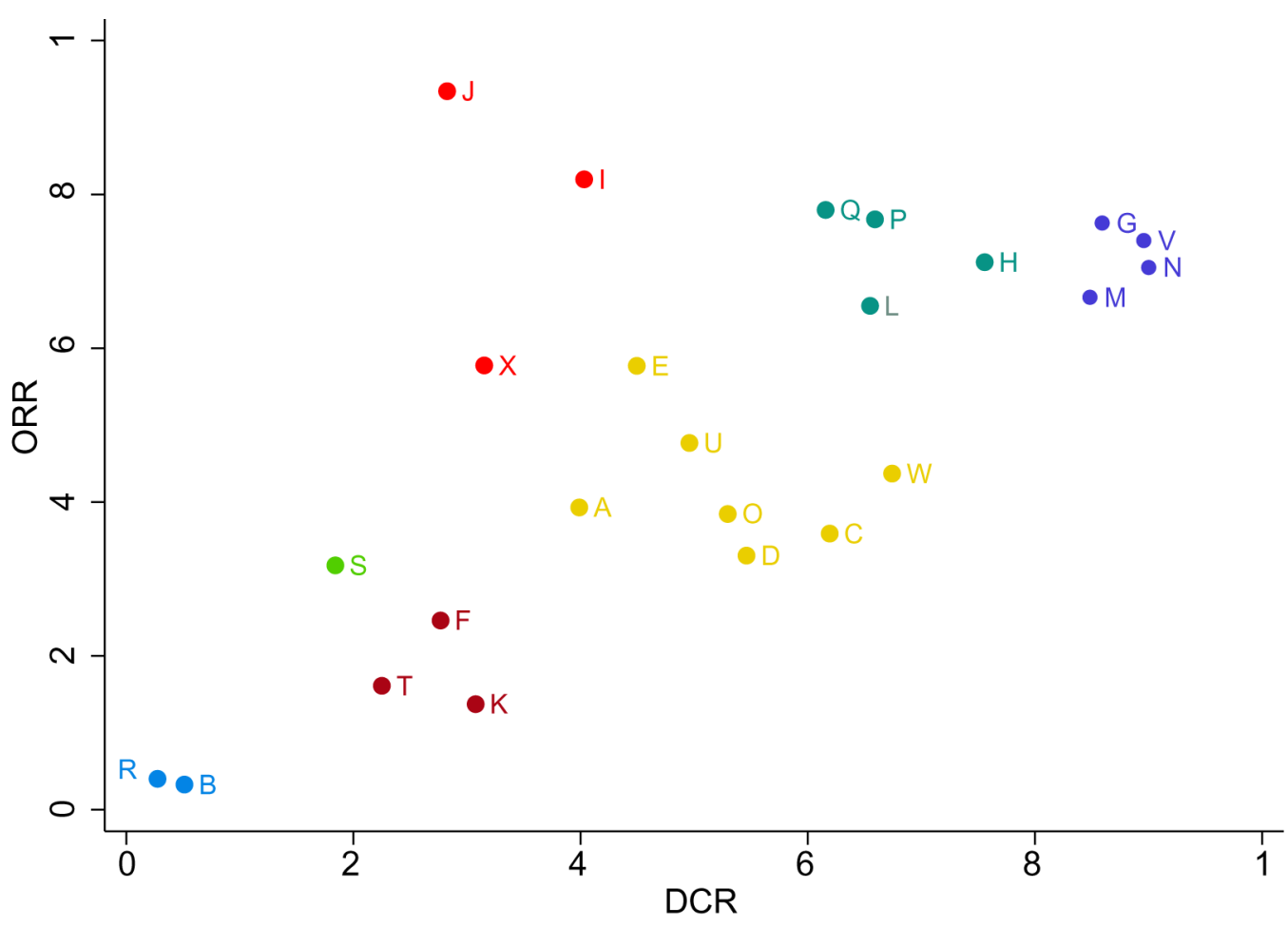

Figure 4: Cluster analysis plots for 24 kinds of chemotherapy regimens in terms of DCR and ORR (DCR $=$ disease control rate; $\mathrm{ORR}=$ overall response rate; A: cisplatin + fluorouracil; B: fluorouracil; C: S-1; D: capecitabine; E: docetaxel + cisplatin; F: irinotecan + cisplatin; G: cisplatin + capecitabine; H: S-1 + cisplatin; I: docetaxel + fluorouracil; J: paclitaxel + fluorouracil; K: fluorouracil + leucovorin; L: docetaxel + oxaliplatin; M: S-1 + irinotecan; N: S-1 + paclitaxel; O: etoposide + adriamycin + cisplatin; P: docetaxel + cisplatin + fluorouracil; Q: etoposide + cisplatin + fluorouracil; R: fluorouracil + adriamycin + mitomycin; S: fluorouracil + adriamycin + methotrexate; T: etoposide + leucovorin + fluorouracil; U: fluorouracil + leucovorine + irinotecan; V: etoposide + cisplatin + capecitabine; W: fluorouracil + leucovorin + cisplatin; $\mathrm{X}$ : cisplatin + etoposide + leucovorin + fluorouracil). 
rates and survival rates in favor of combination regimens [57]. A randomized phase III trial have compared the combinations of fluorouracil with other agents in AGC: infusional 5-FU plus cisplatin (FUP) vs etoposide, LV and 5-FU (ELF) vs 5-FU, doxorubicin and methotrexate (FAMTX) [46]. However, a chemotherapy combination containing infusional 5-FU has the disadvantage of implanting a central venous catheter, and this procedure increases the incidence of subsequent complications, the costs of treatment administration, and the level of discomfort for the patient. The oral fluoropyrimidines (capecitabine and S-1) have shown particular promise, which therefore have the potential to reduce the times of medical examinations related to intravenous injection (i.v.) administration, to reduce the necessary resources for the implantation of the i.v. device, as well as to

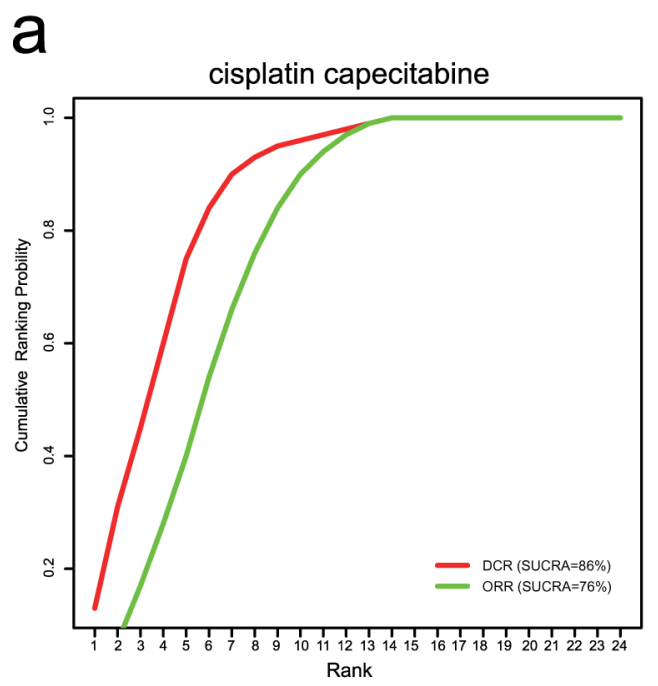

C

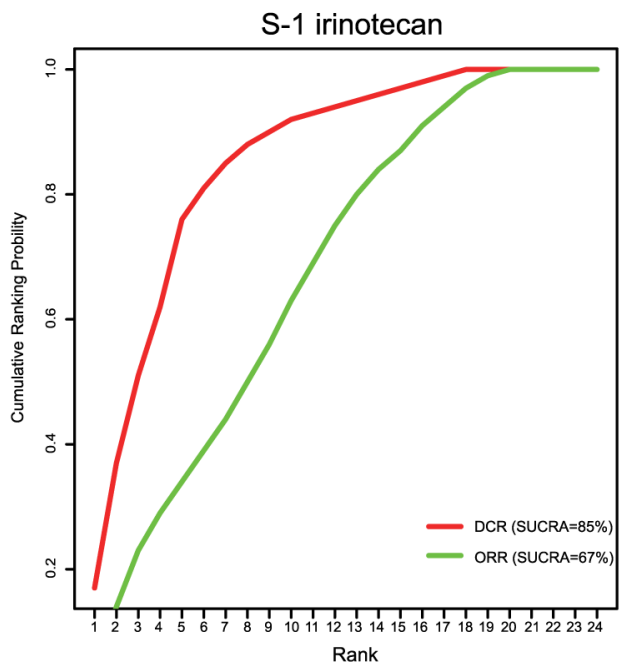

eliminate catheter-related adverse events [58]. Koizumi W proposed that combined with other promising drugs (eg. cisplatin, irinotecan and taxanes), oral fluoropyrimidinebased combination therapy was suggested to yield good results, and especially, the combination of cisplatin and oral fluoropyrimidines showed high efficacy, which was expected to be a standard therapy for AGC [12]. When S-1 was combined with other cytotoxic drugs, such as irinotecan and cisplatin, it was found to be promising, with relatively favorable safety profiles and response rates of $50 \%$ [59]. A randomized phase III study concerning cisplatin and capecitabine $(\mathrm{CX})$ combination therapy in AGC patients showed that CX produced an ORR of $46 \%$ and a median PFS of 5.6 months, which were remarkably better than the poor results with $\mathrm{FU} /$ cisplatin $(\mathrm{CF})$ regimen [60]. All these verified that multi-drug combination

b

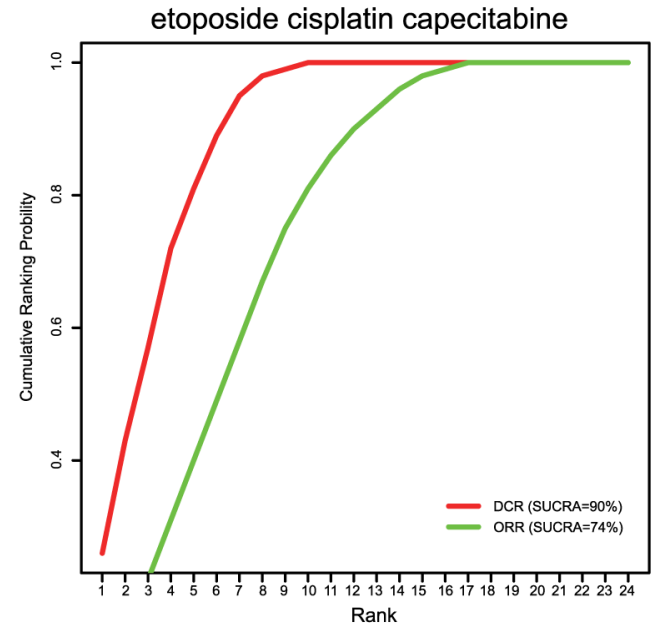

d

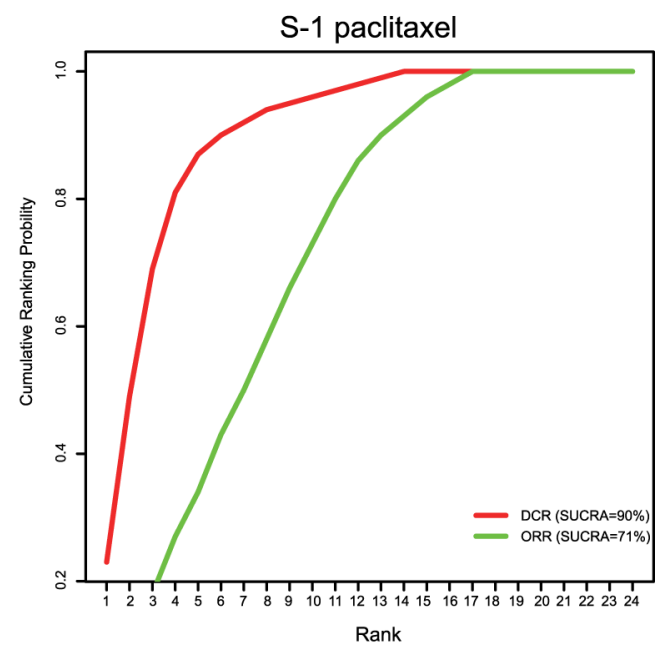

Figure 5: SUCRA plots for chemotherapy regimens of CX, ECX, S-1P and S-1I (a: cisplatin + capecitabine; b: etoposide + cisplatin + capecitabine; c: S-1+ paclitaxel; d: S-1 + irinotecan). 
chemotherapy regimens based on capecitabine and S-1 showed better efficacy than that based on fluorouracil.

Our network meta-analysis offers several important insights: (1) this study is the first network meta-analysis comparing twenty-four chemotherapy regimens in the treatment of $\mathrm{AGC}$, and it bears important clinical implications; (2) we formulated comprehensive search strategy for minimizing possibilities of publication bias; (3) the article referred to both direct and indirect comparisons; (3) the posterior probabilities of SUCRA were utilized to distinguish the slight differences in chemotherapy regimens. However, several limitations of this meta-analysis deserve comment: (1) the presence of missing data in some of the enrolled studies might bias the results; (2) there showed a slight difference in the baseline characteristics of included patients in this network metaanalysis because of different eligible criteria in these studies; (3) since the S-1 agents in enrolled studies were derived from Asian countries, the $\mathrm{S}-1$ regimens are widely used for AGC in Japan [43]. Furthermore, the interethnic differences of capecitabine were observed in genetic changes, which resulting in different efficacy [34]. There might be a certain racial difference, and subgroup analysis could not be carried out for this reason. These limitations might lead to a slight reduction in the validity of our overall results.

The network meta-analysis clearly shows that multi-drug combination chemotherapy regimens based on capecitabine and S-1 might be the best chemotherapy regimen for AGC. However, due to the limitations in our study, our conclusion is needed to be confirmed by a more adequately designed study for future clinical applications.

\section{MATERIALS AND METHODS}

\section{Literature search}

PubMed, Embase, Ovid, EBSCO and Cochrane Library were searched from the inception of each database to July 2015. The search was conducted using the combination of keywords and free words strategy, the terms included "chemotherapy", "pharmacotherapy", "cisplatin", "fluorouracil", "Capecitabine", "Docetaxel", "Paclitaxel", "Oxaliplatin", "S-1" and "gastric cancer", etc. A manual search was also performed for the reference lists of published articles, and literature searches were supplemented by perusing the reference lists of previous meta-analyses.

\section{Inclusion, exclusion criteria and data extraction}

The inclusion criteria included: (1) study design should be randomized controlled trail (RCT); (2) operative methods included chemotherapy agents for the treatment of advanced gastric cancer (AGC) patients; (3) clinically diagnosed AGC patients who only treated with chemotherapy while without any surgical treatments; (4) end outcomes included disease control rate (DCR) and overall response rate (ORR). The exclusion criteria included: (1) studies with insufficient data; (2) non-RCTs, duplicated publications and AGC patients received surgical treatment or radiotherapy. Two reviewers extracted data from the enrolled studies using a specifically designed form. Additionally, a third reviewer was consulted if agreement could not be reached between these two reviewers.

\section{Statistical analysis}

First, we conducted pair-wise meta-analyses of direct evidence by using the random-effects model, which was supplemented with $\mathrm{R}$ version 3.2.1 and the Meta package. Second, random-effects network meta-analysis was performed with the gemtc package. Lu and Ades reported that by linking to Open BUGS, network metaanalysis models the relative effects fitting a generalized linear model (GLM) under the Bayesian framework [61]. The relative effects were converted to a probability, which could judge whether a treatment was best or worst, with the surface under the cumulative ranking (SUCRA) curve of each treatment [62] presented as a percentage, ranging from $0 \% \sim 100 \%$ ( $0 \%$ : worst; $100 \%$ : best). Based on SUCRA curve, the summary estimates were showed in league tables through ranking the treatments according to priority of the most significant influence on the outcome under consideration [62]. Our command of cluster rank was used in the production of clustered ranking plots in STATA. Outcome1 and outcome2 were regarded as the data variables which containing the SUCRA values for all the treatments in a network. The different colors referred to the estimated clusters, which were used to group the treatments in accordance with their similarity in terms of both outcomes. The concept of design-bytreatment interaction supplied a useful general framework to explore the inconsistency. Particularly, the application of design-by-treatment interactions successfully dealt with complications arising from the multi-arm trials in an evidence network [63]. Lu and Ades also described that a model motivated mainly by loop inconsistency. We provided all models by using mvmeta, which was a Stata (Stata Corp LP. College Station, TX, USA) macro conducted random-effects multivariate meta-regression by using the restricted maximum likelihood [64].

\section{Abbreviations}

$\mathrm{CF}$ : cisplatin + fluorouracil, DC: docetaxel + cisplatin, $\mathrm{CI}$ : irinotecan + cisplatin, $\mathrm{CX}$ : cisplatin + capecitabine, S-1C: S-1 + cisplatin, DF: docetaxel + fluorouracil, PF: paclitaxel + fluorouracil, FL: fluorouracil + leucovorin, DO: docetaxel + oxaliplatin, S-1I: S-1 + irinotecan, S-1P: S-1 + paclitaxel, EAC: etoposide + 
adriamycin + cisplatin, DCF: docetaxel + cisplatin + fluorouracil, ECF: etoposide + cisplatin + fluorouracil, FAM: fluorouracil + adriamycin + mitomycin, FAMTX: fluorouracil + adriamycin + methotrexate, ELF: etoposide + leucovorin + fluorouracil, FLI: fluorouracil + leucovorin + irinotecan, ECX: etoposide + cisplatin + capecitabine, FLC: fluorouracil + leucovorin + cisplatin, CELF: cisplatin + etoposide + leucovorin fluorouracil

\section{ACKNOWLEDGMENTS}

The authors wish to express their gratitude to reviewers for their critical comments.

\section{CONFLICTS OF INTEREST}

There was no conflicts of interest existing in this paper.

\section{REFERENCES}

1. Parkin DM, Bray F, Ferlay J, Pisani P. Global cancer statistics, 2002. CA Cancer J Clin. 2005; 55:74-108.

2. Yang XJ, Huang CQ, Suo T, Mei LJ, Yang GL, Cheng FL, Zhou YF, Xiong B, Yonemura Y, Li Y. Cytoreductive surgery and hyperthermic intraperitoneal chemotherapy improves survival of patients with peritoneal carcinomatosis from gastric cancer: final results of a phase III randomized clinical trial. Ann Surg Oncol. 2011; 18:1575-1581.

3. de Martel C, Forman D, Plummer M. Gastric cancer: epidemiology and risk factors. Gastroenterol Clin North Am. 2013; 42:219-240.

4. Guggenheim DE, Shah MA. Gastric cancer epidemiology and risk factors. J Surg Oncol. 2013; 107:230-236.

5. Kim JA, Lee J, Han B, Park SH, Park JO, Park YS, Lim HY, Kang WK. Docetaxel/cisplatin followed by FOLFIRI versus the reverse sequence in metastatic gastric cancer. Cancer Chemother Pharmacol. 2011; 68:177-184.

6. Scartozzi M, Galizia E, Verdecchia L, Berardi R, Antognoli S, Chiorrini S, Cascinu S. Chemotherapy for advanced gastric cancer: across the years for a standard of care. Expert Opin Pharmacother. 2007; 8:797-808.

7. Popov IP, Jelic SB, Krivokapic ZV, Jezdic SD, Pesko PM, Micev MT, Babic DR. Bimonthly $24 \mathrm{~h}$ infusion of high-dose 5-fluorouracil vs EAP regimen in patients with advanced gastric cancer. A randomized phase II study. Med Oncol. 2008; 25:73-80.

8. Cavanna L, Artioli F, Codignola C, Lazzaro A, Rizzi A, Gamboni A, Rota L, Rodino C, Boni F, Iop A, Zaniboni A. Oxaliplatin in combination with 5-fluorouracil (5-FU) and leucovorin (LV) in patients with metastatic gastric cancer (MGC). Am J Clin Oncol. 2006; 29:371-375.

9. Ohtsu A, Shimada Y, Shirao K, Boku N, Hyodo I, Saito H, Yamamichi N, Miyata Y, Ikeda N, Yamamoto S, Fukuda H,
Yoshida S, Japan Clinical Oncology Group S. Randomized phase III trial of fluorouracil alone versus fluorouracil plus cisplatin versus uracil and tegafur plus mitomycin in patients with unresectable, advanced gastric cancer: The Japan Clinical Oncology Group Study (JCOG9205). J Clin Oncol. 2003; 21:54-59.

10. Bolke E, Peiper M, Budach W. Capecitabine and oxaliplatin for advanced esophagogastric cancer. N Engl J Med. 2008; 358:1965; author reply 1965.

11. Kang YK, Kang WK, Shin DB, Chen J, Xiong J, Wang J, Lichinitser M, Guan Z, Khasanov R, Zheng L, Philco-Salas M, Suarez T, Santamaria J, et al. Capecitabine/cisplatin versus 5-fluorouracil/cisplatin as first-line therapy in patients with advanced gastric cancer: a randomised phase III noninferiority trial. Ann Oncol. 2009; 20:666-673.

12. Koizumi W, Narahara H, Hara T, Takagane A, Akiya T, Takagi M, Miyashita K, Nishizaki T, Kobayashi O, Takiyama W, Toh Y, Nagaie T, Takagi S, et al. S-1 plus cisplatin versus S-1 alone for first-line treatment of advanced gastric cancer (SPIRITS trial): a phase III trial. Lancet Oncol. 2008; 9:215-221.

13. Sakamoto J, Chin K, Kondo K, Kojima H, Terashima M, Yamamura Y, Tsujinaka T, Hyodo I, Koizumi W and Clinical Study Group of C. Phase II study of a 4-week capecitabine regimen in advanced or recurrent gastric cancer. Anticancer Drugs. 2006; 17:231-236.

14. Wesolowski R, Lee C, Kim R. Is there a role for second-line chemotherapy in advanced gastric cancer? Lancet Oncol. 2009; 10:903-912.

15. Boku N, Yamamoto S, Fukuda H, Shirao K, Doi T, Sawaki A, Koizumi W, Saito H, Yamaguchi K, Takiuchi H, Nasu J, Ohtsu A, Gastrointestinal Oncology Study Group of the Japan Clinical Oncology G. Fluorouracil versus combination of irinotecan plus cisplatin versus S-1 in metastatic gastric cancer: a randomised phase 3 study. Lancet Oncol. 2009; 10:1063-1069.

16. Lumley T. Network meta-analysis for indirect treatment comparisons. Stat Med. 2002; 21:2313-2324.

17. Bouche O, Raoul JL, Bonnetain F, Giovannini M, Etienne PL, Lledo G, Arsene D, Paitel JF, Guerin-Meyer V, Mitry E, Buecher B, Kaminsky MC, Seitz JF, et al. Randomized multicenter phase II trial of a biweekly regimen of fluorouracil and leucovorin (LV5FU2), LV5FU2 plus cisplatin, or LV5FU2 plus irinotecan in patients with previously untreated metastatic gastric cancer: a Federation Francophone de Cancerologie Digestive Group Study-FFCD 9803. J Clin Oncol. 2004; 22:4319-4328.

18. Bugat R. Irinotecan in the treatment of gastric cancer. Annals of Oncology. 2003; 14:ii37-ii40.

19. Cocconi G, Bella M, Zironi S, Algeri R, Di Costanzo F, De Lisi V, Luppi G, Mazzocchi B, Rodino C, Soldani M. Fluorouracil, doxorubicin, and mitomycin combination versus PELF chemotherapy in advanced gastric cancer: a prospective randomized trial of the Italian Oncology Group for Clinical Research. J Clin Oncol. 1994; 12:2687-2693. 
20. Cocconi G, Carlini P, Gamboni A, Gasperoni S, Rodino C, Zironi S, Bisagni G, Porrozzi S, Cognetti F, Di Costanzo F, Canaletti R, Ruggeri EM, Camisa R, Pucci F. Cisplatin, epirubicin, leucovorin and 5-fluorouracil (PELF) is more active than 5-fluorouracil, doxorubicin and methotrexate (FAMTX) in advanced gastric carcinoma. Ann Oncol. 2003; 14:1258-1263.

21. Kelsen D, Atiq OT, Saltz L, Niedzwiecki D, Ginn D, Chapman D, Heelan R, Lightdale C, Vinciguerra V, Brennan M. FAMTX versus etoposide, doxorubicin, and cisplatin: a random assignment trial in gastric cancer. J Clin Oncol. 1992; 10:541-548.

22. Kim JA, Lee J, Han B, Park SH, Park JO, Park YS, Lim HY, Kang WK. Docetaxel/cisplatin followed by FOLFIRI versus the reverse sequence in metastatic gastric cancer. Cancer Chemotherapy and Pharmacology. 2011; 68:177-184.

23. Kim NK, Park YS, Heo DS, Suh C, Kim SY, Park KC, Kang YK, Shin DB, Kim HT, Kim HJ. A phase III randomized study of 5-fluorouracil and cisplatin versus 5-fluorouracil, doxorubicin, and mitomycin $\mathrm{C}$ versus 5-fluorouracil alone in the treatment of advanced gastric cancer. Cancer. 1993; 71:3813-3818.

24. Kim YS, Sym SJ, Park SH, Park I, Hong J, Ahn HK, Park J, Cho EK, Lee WK, Chung M, Lee JH, Shin DB. A randomized phase II study of weekly docetaxel/cisplatin versus weekly docetaxel/oxaliplatin as first-line therapy for patients with advanced gastric cancer. Cancer Chemother Pharmacol. 2014; 73:163-169.

25. Komatsu Y, Takahashi Y, Kimura Y, Oda H, Tajima Y, Tamura S, Sakurai J, Wakasugi T, Tatebe S, Takahashi M, Sakata Y, Kitajima M, Sakamoto J, Saji S. Randomized phase II trial of first-line treatment with tailored irinotecan and S-1 therapy versus S-1 monotherapy for advanced or recurrent gastric carcinoma (JFMC31-0301). Anticancer Drugs. 2011; 22:576-583.

26. Lee JL, Kang YK, Kang HJ, Lee KH, Zang DY, Ryoo BY, Kim JG, Park SR, Kang WK, Shin DB, Ryu MH, Chang HM, Kim TW, et al. A randomised multicentre phase II trial of capecitabine vs S-1 as first-line treatment in elderly patients with metastatic or recurrent unresectable gastric cancer. British Journal of Cancer. 2008; 99:584-590.

27. Lim do H, Park SH, Park KW, Kang JH, Oh SY, Hwang IG, Kwon JM, Lee SC, Lee HY, Kim HS, Lim HY, Kang WK. Retrospective analyses of cisplatin-based doublet combination chemotherapy in patients with advanced gastric cancer. BMC Cancer. 2010; 10:257-267.

28. Lutz MP, Wilke H, Wagener DJ, Vanhoefer U, Jeziorski K, Hegewisch-Becker S, Balleisen L, Joossens E, Jansen RL, Debois M, Bethe U, Praet M, Wils J, Van Cutsem E. Weekly infusional high-dose fluorouracil (HD-FU), HD-FU plus folinic acid (HD-FU/FA), or HD-FU/FA plus biweekly cisplatin in advanced gastric cancer: randomized phase II trial 40953 of the European Organisation for Research and Treatment of Cancer Gastrointestinal Group and the
Arbeitsgemeinschaft Internistische Onkologie. J Clin Oncol. 2007; 25:2580-2585.

29. Mochiki E, Ogata K, Ohno T, Toyomasu Y, Haga N, Fukai Y, Aihara R, Ando H, Uchida N, Asao T, Kuwano H. Phase II multi-institutional prospective randomised trial comparing S-1paclitaxel with S-1 cisplatin in patients with unresectable and/or recurrent advanced gastric cancer. British Journal of Cancer. 2012; 107:31-36.

30. Moehler M, Eimermacher A, Siebler J, Hohler T, Wein A, Menges M, Flieger D, Junginger T, Geer T, Gracien E, Galle PR, Heike M. Randomised phase II evaluation of irinotecan plus high-dose 5-fluorouracil and leucovorin (ILF) vs 5-fluorouracil, leucovorin, and etoposide (ELF) in untreated metastatic gastric cancer. British Journal of Cancer. 2005; 92:2122-2128.

31. Nakashima K, Hironaka S, Boku N, Onozawa Y, Fukutomi A, Yamazaki K, Yasui H, Taku K, Kojima T, Machida N. Irinotecan plus cisplatin therapy and $\mathrm{S}-1$ plus cisplatin therapy for advanced or recurrent gastric cancer in a single institution. Jpn J Clin Oncol. 2008; 38:810-815.

32. Narahara H, Iishi H, Imamura H, Tsuburaya A, Chin K, Imamoto H, Esaki T, Furukawa H, Hamada C, Sakata Y. Randomized phase III study comparing the efficacy and safety of irinotecan plus S-1 with S-1 alone as first-line treatment for advanced gastric cancer (study GC0301/TOP002). Gastric Cancer. 2011; 14:72-80.

33. Nishikawa K, Morita S, Matsui T, Kobayashi M, Takeuchi Y, Takahashi I, Sato S, Miyashita Y, Tsuburaya A, Sakamoto J, Kakeji Y, Baba H. A randomized phase-II trial comparing sequential and concurrent paclitaxel with oral or parenteral fluorinated pyrimidines for advanced or metastatic gastric cancer. Gastric Cancer. 2012; 15:363-369.

34. Ocvirk J, Rebersek M, Skof E, Hlebanja Z, Boc M. Randomized prospective phase ii study to compare the combination chemotherapy regimen epirubicin, cisplatin, and 5-fluorouracil with epirubicin, cisplatin, and capecitabine in patients with advanced or metastatic gastric cancer. American Journal of Clinical Oncology: Cancer Clinical Trials. 2012; 35:237-241.

35. Ohkuwa M, Ohtsu A, Boku N, Yoshida S, Miyata Y, Shirao K, Shimada Y, Kurihara M. Long-term results for patients with unresectable gastric cancer who received chemotherapy in the Japan Clinical Oncology Group (JCOG) trials. Gastric Cancer. 2000; 3:145-150.

36. Ohtsu A, Shimada Y, Shirao K, Boku N, Hyodo I, Saito H, Yamamichi N, Miyata Y, Ikeda N, Yamamoto S, Fukuda H, Yoshida S. Randomized phase III trial of fluorouracil alone versus fluorouracil plus cisplatin versus uracil and tegafur plus mitomycin in patients with unresectable, advanced gastric cancer: The Japan Clinical Oncology Group Study (JCOG9205). J Clin Oncol. 2003; 21:54-59.

37. Park SH, Lee WK, Chung M, Lee Y, Han SH, Bang SM, Cho EK, Shin DB, Lee JH. Paclitaxel versus docetaxel for advanced gastric cancer: a randomized phase II trial 
in combination with infusional 5-fluorouracil. Anticancer Drugs. 2006; 17:225-229.

38. Popov IP, Jelic SB, Krivokapic ZV, Jezdic SD, Pesko PM, Micev MT, Babic DR. Bimonthly $24 \mathrm{~h}$ infusion of high-dose 5-fluorouracil vs EAP regimen in patients with advanced gastric cancer: A randomized phase II study. Medical Oncology. 2008; 25:73-80.

39. Roth AD, Fazio N, Stupp R, Falk S, Bernhard J, Saletti P, Koberle D, Borner MM, Rufibach K, Maibach R, Wernli M, Leslie M, Glynne-Jones R, et al. Docetaxel, cisplatin, and fluorouracil; docetaxel and cisplatin; and epirubicin, cisplatin, and fluorouracil as systemic treatment for advanced gastric carcinoma: a randomized phase II trial of the Swiss Group for Clinical Cancer Research. J Clin Oncol. 2007; 25:3217-3223.

40. Sadighi S, Mohagheghi MA, Montazeri A, Sadighi Z. Quality of life in patients with advanced gastric cancer: A randomized trial comparing docetaxel, cisplatin, 5-FU (TCF) with epirubicin, cisplatin, 5-FU (ECF). BMC Cancer. 2006; 6:1-6.

41. Seol YM, Song MK, Choi YJ, Kim GH, Shin HJ, Song GA, Chung JS, Cho GJ. Oral fluoropyrimidines (capecitabine or S-1) and cisplatin as first line treatment in elderly patients with advanced gastric cancer: a retrospective study. Jpn J Clin Oncol. 2009; 39:43-48.

42. Shitara K, Sawaki A, Matsuo K, Kondo C, Takahari D, Ura T, Tajika M, Niwa Y, Muro K. A retrospective comparison of S-1 plus cisplatin and capecitabine plus cisplatin for patients with advanced or recurrent gastric cancer. Int J Clin Oncol. 2013; 18:539-546.

43. Sugimoto N, Fujitani K, Imamura H, Uedo N, Iijima S, Imano M, Shimokawa T, Kurokawa Y, Furukawa H, Goto M. Randomized phase II trial of S-1 plus irinotecan versus S-1 plus paclitaxel as first-line treatment for advanced gastric cancer (OGSG0402). Anticancer Res. 2014; 34:851-857.

44. Thuss-Patience PC, Kretzschmar A, Repp M, Kingreen D, Hennesser D, Micheel S, Pink D, Scholz C, Dorken B, Reichardt P. Docetaxel and continuous-infusion fluorouracil versus epirubicin, cisplatin, and fluorouracil for advanced gastric adenocarcinoma: a randomized phase II study. J Clin Oncol. 2005; 23:494-501.

45. Van Cutsem E, Moiseyenko VM, Tjulandin S, Majlis A, Constenla M, Boni C, Rodrigues A, Fodor M, Chao Y, Voznyi E, Risse ML, Ajani JA. Phase III study of docetaxel and cisplatin plus fluorouracil compared with cisplatin and fluorouracil as first-line therapy for advanced gastric cancer: a report of the V325 Study Group. J Clin Oncol. 2006; 24:4991-4997.

46. Vanhoefer U, Rougier P, Wilke H, Ducreux MP, Lacave AJ, Van Cutsem E, Planker M, Santos JG, Piedbois P, Paillot B, Bodenstein H, Schmoll HJ, Bleiberg H, et al. Final results of a randomized phase III trial of sequential highdose methotrexate, fluorouracil, and doxorubicin versus etoposide, leucovorin, and fluorouracil versus infusional fluorouracil and cisplatin in advanced gastric cancer: A trial of the European Organization for Research and Treatment of Cancer Gastrointestinal Tract Cancer Cooperative Group. J Clin Oncol. 2000; 18:2648-2657.

47. Wang X, Wang ML, Zhou LY, Lu XY, Yang JF, Yu HG. Randomized phase II study comparing paclitaxel with S-1 vs. S-1 as first-line treatment in patients with advanced gastric cancer. Clin Transl Oncol. 2013; 15:836-842.

48. Waters JS, Norman A, Cunningham D, Scarffe JH, Webb A, Harper P, Joffe JK, Mackean M, Mansi J, Leahy M, Hill A, Oates J, Rao S, et al. Long-term survival after epirubicin, cisplatin and fluorouracil for gastric cancer: results of a randomized trial. Br J Cancer. 1999; 80:269-272.

49. Wils JA, Klein HO, Wagener DJ, Bleiberg H, Reis H, Korsten F, Conroy T, Fickers M, Leyvraz S, Buyse M. Sequential high-dose methotrexate and fluorouracil combined with doxorubicin--a step ahead in the treatment of advanced gastric cancer: a trial of the European Organization for Research and Treatment of Cancer Gastrointestinal Tract Cooperative Group. J Clin Oncol. 1991; 9:827-831.

50. Yun JA, Kong JH, Kim JA, Lee SH, Lee JY, Park SH, Park JO, Park YS, Lim HY, Kang WK. A randomized phase II study of combination chemotherapy with epirubicin, cisplatin and capecitabine $(\mathrm{ECX})$ or cisplatin and capecitabine $(\mathrm{CX})$ in advanced gastric cancer (AGC): A preliminary safety results. European Journal of Cancer, Supplement. 2009; 7:363.

51. Mochiki E, Ogata K, Ohno T, Toyomasu Y, Haga N, Fukai Y, Aihara R, Ando H, Uchida N, Asao T, Kuwano H, North Kanto Gastric Cancer Study G. Phase II multi-institutional prospective randomised trial comparing $\mathrm{S}-1+$ paclitaxel with $\mathrm{S}-1+$ cisplatin in patients with unresectable and/or recurrent advanced gastric cancer. Br J Cancer. 2012; 107:31-36.

52. Evans TR, Pentheroudakis G, Paul J, McInnes A, Blackie R, Raby N, Morrison R, Fullarton GM, Soukop M, McDonald AC. A phase I and pharmacokinetic study of capecitabine in combination with epirubicin and cisplatin in patients with inoperable oesophago-gastric adenocarcinoma. Ann Oncol. 2002; 13:1469-1478.

53. Nishiyama M, Eguchi H. Pharmacokinetics and pharmacogenomics in gastric cancer chemotherapy. Adv Drug Deliv Rev. 2009; 61:402-407.

54. Lee JL, Kang YK, Kang HJ, Lee KH, Zang DY, Ryoo BY, Kim JG, Park SR, Kang WK, Shin DB, Ryu MH, Chang HM, Kim TW, et al. A randomised multicentre phase II trial of capecitabine vs S-1 as first-line treatment in elderly patients with metastatic or recurrent unresectable gastric cancer. Br J Cancer. 2008; 99:584-590.

55. Ajani JA, Rodriguez W, Bodoky G, Moiseyenko V, Lichinitser M, Gorbunova V, Vynnychenko I, Garin A, Lang I, Falcon S. Multicenter phase III comparison of cisplatin/S-1 with cisplatin/infusional fluorouracil in 
advanced gastric or gastroesophageal adenocarcinoma study: the FLAGS trial. J Clin Oncol. 2010; 28:1547-1553.

56. Cunningham D, Okines AF, Ashley S. Capecitabine and oxaliplatin for advanced esophagogastric cancer. N Engl J Med. 2010; 362:858-859.

57. Tsuji A, Shima Y, Morita S, Uchida M, Okamoto K, Morita M, Horimi T, Shirasaka T. Combination chemotherapy of S-1 and low-dose twice-weekly cisplatin for advanced and recurrent gastric cancer in an outpatient setting: a retrospective study. Anticancer Res. 2008; 28:1433-1438.

58. Pozzo C, Barone C. Is there an optimal chemotherapy regimen for the treatment of advanced gastric cancer that will provide a platform for the introduction of new biological agents? Oncologist. 2008; 13:794-806.

59. Masuzawa T, Fujiwara Y, Okada K, Nakamura A, Takiguchi S, Nakajima K, Miyata H, Yamasaki M, Kurokawa Y, Osawa R, Takeda K, Yoshida K, Tsunoda T, et al. Phase I/II study of S-1 plus cisplatin combined with peptide vaccines for human vascular endothelial growth factor receptor 1 and 2 in patients with advanced gastric cancer. Int J Oncol. 2012; 41:1297-1304.
60. Yun J, Lee J, Park SH, Park JO, Park YS, Lim HY, Kang WK. A randomised phase II study of combination chemotherapy with epirubicin, cisplatin and capecitabine (ECX) or cisplatin and capecitabine $(\mathrm{CX})$ in advanced gastric cancer. Eur J Cancer. 2010; 46:885-891.

61. Lu G, Ades AE. Combination of direct and indirect evidence in mixed treatment comparisons. Stat Med. 2004; 23:3105-3124.

62. Salanti G, Ades AE, Ioannidis JP. Graphical methods and numerical summaries for presenting results from multipletreatment meta-analysis: an overview and tutorial. J Clin Epidemiol. 2011; 64:163-171.

63. Higgins JP, Jackson D, Barrett JK, Lu G, Ades AE, White IR. Consistency and inconsistency in network metaanalysis: concepts and models for multi-arm studies. Res Synth Methods. 2012; 3:98-110.

64. White IR, Barrett JK, Jackson D, Higgins JP. Consistency and inconsistency in network meta-analysis: model estimation using multivariate meta-regression. Res Synth Methods. 2012; 3:111-125. 